\title{
MER-ClASS ROVER INVESTIGATIONS OF MARS IN THE COMING DECADES
}

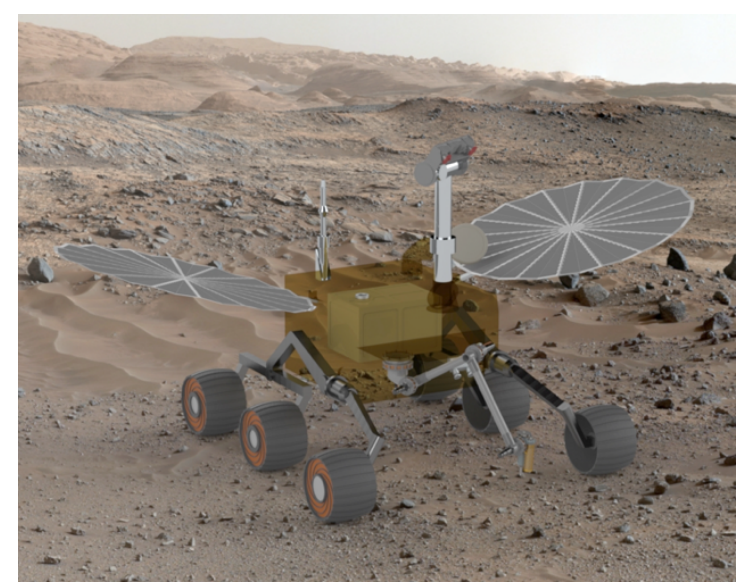

David Blake ${ }^{1}$, Kris Zacny ${ }^{2}$, Thomas Bristow ${ }^{1}$, Shaunna Morrison ${ }^{3}$, Philippe Sarrazin ${ }^{4}$, Elizabeth Rampe $^{5}$, Valerie Tu ${ }^{6}$, Michael T. Thorpe ${ }^{5}$, Valerie Payre ${ }^{7}$, Rebecca Smith ${ }^{8}$, Noel Scudder ${ }^{9}$

Candice C. Bedford ${ }^{10}$ and Erwin Dehouck ${ }^{11}$

${ }^{1}$ Exobiology Branch, MS 239-4, NASA Ames Research Center, Moffett Field, CA 94035 (david.blake@nasa.gov; $\underline{650-604-4816}$ )

${ }^{2}$ Honeybee Robotics, Pasadena, CA USA

3 Carnegie Institution for Science, Washington, DC USA;

4 ExaminArt LLC, Mountain View, CA USA

${ }^{5}$ Astromaterials Research and Exploration Science Division, NASA Johnson Space Center Houston, TX USA

6 Jacobs/JETS at NASA Johnson Space Center, Houston, TX USA

${ }^{7}$ Rice University, Houston, TX USA

${ }^{8}$ Stony Brook University, Stony Brook, NY USA

9 Purdue University, West Lafayette, IN USA

${ }^{10}$ Lunar and Planetary Institute, Houston, TX USA

${ }^{11}$ LGL-TPE, University de Lyon, FR

\section{SUMMARY}

In order to understand the geology of Mars, its early habitability and its potential to support InSitu Resource Utilization (ISRU) and eventual human habitation, full and comprehensive science investigations are needed at many diverse sites. With regard to geologic environment, habitability potential and biosignature identification, there are 3 principal characteristics that define rocks or soil: Structure (mineralogy as defined by crystal structure), Elemental Composition, and Morphology. The two subsequent decades of spacecraft instrument development and miniaturization following the deployment of the Mars Exploration Rover (MER) missions have allowed for Flagship-class instrumentation to be packaged in payloads suitable for MER rover architectures. A MER-class rover equipped with a powdering drill, XRD/XRF and arm-based elemental imager, along with context instruments such as a Mast camera and hand-lens imager, will provide a comprehensive characterization of Mars surface regolith. A cookie-cutter approach to the development of a MER-class architecture suitable for multiple mission opportunities would reduce cost and risk. Only by accessing and fully characterizing multiple sites representing the full diversity of geologic and morphologic features on Mars will we be able to fully elucidate its early history and habitability potential. 
INTRODUCTION: It is likely that the level-of-effort and cost of Mars Sample Return will preclude Flagship-class missions to Mars for the indefinite future, limiting a full and comprehensive characterization of the Mars surface to only two sites: Gale and Jezero Craters. However, dozens of geologically diverse and scientifically compelling landing sites were characterized during the MER, MSL and Mars 2020 site selection workshops [1-3]. In order to understand the geology of Mars, its early habitability and its potential to support ISRU and eventual human habitation, full and comprehensive science investigations are needed at many diverse sites.

The MER rovers Spirit and Opportunity were among the most successful landed Mars missions of all time, exceeding expectations for mission duration and science return. This legacy of mission success and scientific accomplishment must be continued. Moreover, two further decades of spacecraft instrument development and miniaturization now allow for Flagship-class instrumentation to be packaged in payloads suitable for MER rover architectures [4-5].

With regard to geologic environment, habitability potential and biosignature identification, there are 3 principal characteristics that define rocks or soil: Structure (mineralogy as defined by crystal structure), Elemental Composition, and Morphology. Mineralogical analysis alone can

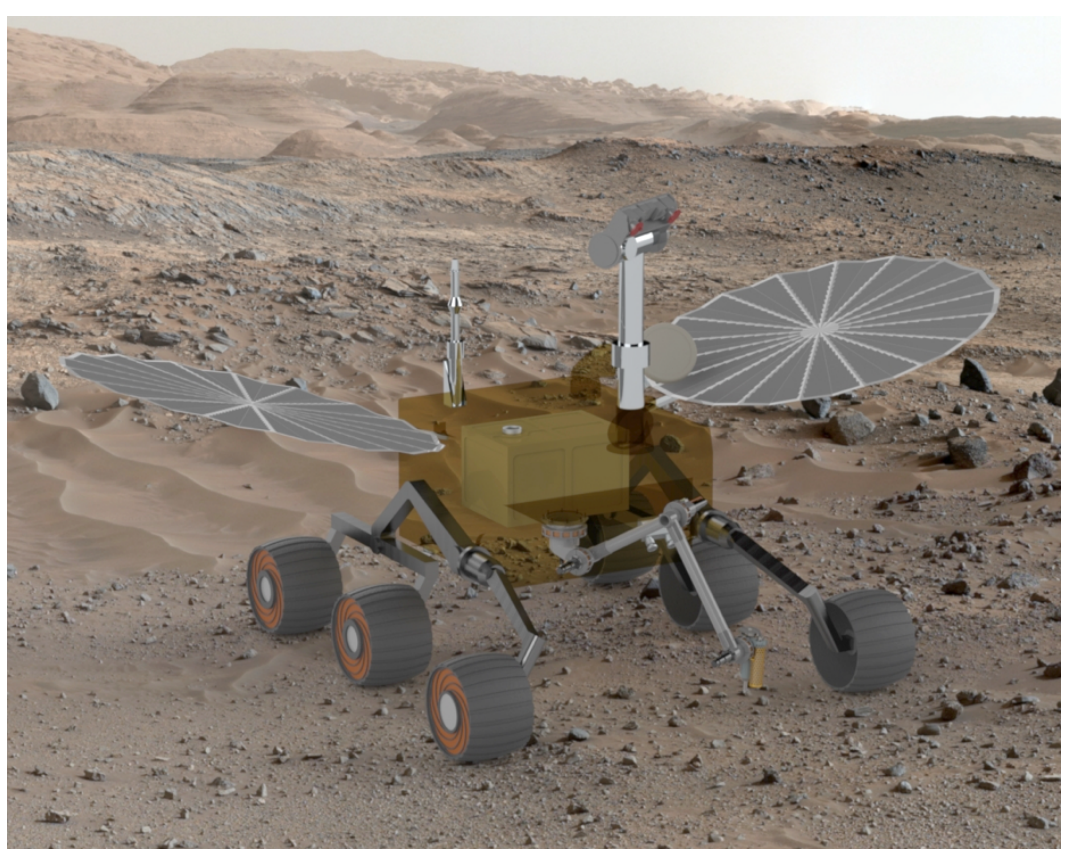

Figure 1. Implementation of a Powder Collection and Delivery (PCD) system and Instrument Sample Manipulator (ISM) on a MER sized rover (as modeled $2.0 \mathrm{X} 1.0 \mathrm{X} 1.0 \mathrm{~m}$, $120-150 \mathrm{~kg}$ ). The PCD is fitted to the arm of the rover and collects powdered samples from the ground. The powder is delivered to an $\mathrm{XRD} / \mathrm{XRF}$ instrument visible inside the rover and hosting the ISM. The proposed technology will enable definitive mineralogical analysis in smaller rovers. be used to fully characterize a geologic environment. Elemental analysis is useful to determine the composition of X-ray amorphous material (if present) and to identify minor or trace elements suggestive of secondary processes. Morphology provides spatial context and timing. Are there veins, concretions, macroscopic crystals present in the sampled volume?

A MER-class payload that would provide a full and comprehensive characterization of a scientifically compelling site on Mars could be (for example): A Robotic Arm equipped with a mini-powdering drill, a Rotary Abrasion Tool (RAT) and an imaging X-ray Spectrometer. Drilled 
and powdered materials could be delivered to an Xray Diffraction / X-ray Fluorescence instrument (XRD/XRF) in the body of the rover, to provide definitive and quantitative mineralogy of the drilled materials. A mast camera or arm-mounted hand lens camera could provide context for the measurements. Figure 1 shows an example MERclass rover with an XRD and powdering drill and Figure 2 shows an implementation of a

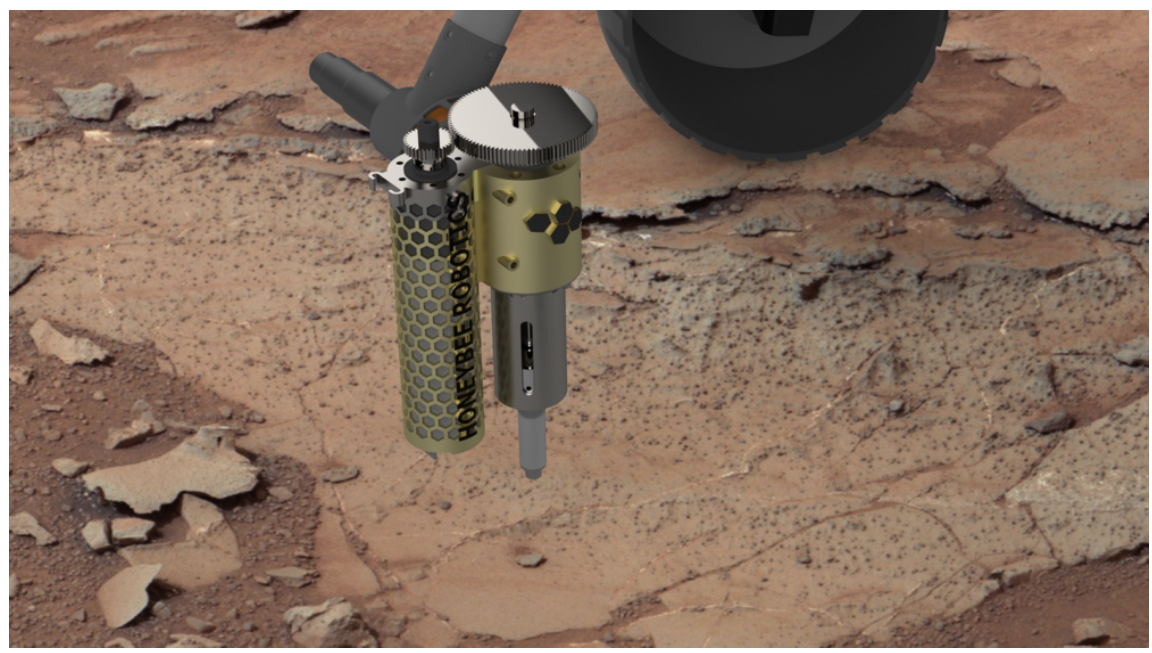

Figure 2. Implementation of a powder collection system based on a miniaturized design of Honeybee Robotics powder drill [6]. powder collection system.

(Mars Science Laboratory CheMin Instrument): As the first crystallography instrument ever flown in space, the XRD/XRF instrument CheMin's mineralogical analyses have been critical to a number of first-of-their-kind achievements. CheMin's third analysis, "Cumberland" is shown here in its entirety to illustrate the power and unique capability of X-ray diffraction in characterizing complex mineral assemblages. Tables 1-3 illustrate the data set obtained from this measurement.

\section{EXAMPLE XRD/XRF ANALYSIS - CUMBERLAND MUdSTONe, GALE CRATER [7,8]}

Table 1 shows the mineral identifications and elemental compositions of major crystalline phases obtained through Rietveld refinement [9]. In addition to determining mineral compositions, refined lattice parameters are also used to measure cation deficiency in magnetite and the structural state of the potassium feldspar [10-11]. Clay minerals are identified and quantified using FULLPAT analysis [12]. The clay mineral in Cumberland is identified as a smectite from the position of its 001 peak. The position of the $02 l$ diffraction band of the smectite indicates that it is a Fe-rich and trioctahedral. The proportions of crystalline minerals, clay minerals and

Table 1. Mineral Abundances in the Cumberland Mudstone

\begin{tabular}{|c|c|c|}
\hline Mineral & Wt.\% & Composition \\
\hline Plagioclase Feldspar $^{1}$ & $42.8(2)$ & $\mathrm{Ca}_{0.33(5)} \mathrm{Na}_{0.67(5)} \mathrm{Al}_{1.33} \mathrm{Si}_{2.67} \mathrm{O}_{8}$ \\
\hline Pigeonite $^{1}$ & $17.0(11)$ & $\mathrm{Mg}_{1.08(11)} \mathrm{Fe}_{0.78(16)} \mathrm{Ca}_{0.14(8)} \mathrm{Si}_{2} \mathrm{O}_{6}$ \\
\hline Orthopyroxene & $14.5(8)$ & $\mathrm{Mg}_{0.83(8)} \mathrm{Fe}_{1.15(10)} \mathrm{Ca}_{0.02(5)} \mathrm{Si}_{2} \mathrm{O}_{6}$ \\
\hline Magnetite $^{2}$ & $11.5(4)$ & $\mathrm{Fe}_{2.81(5)} \quad 0_{0.19} \mathrm{O}_{4}$ \\
\hline Sanidine $^{1,3}$ & $4.9(7)$ & $\mathrm{K}_{0.77(19)} \mathrm{Na}_{0.23} \mathrm{AlSi}_{3} \mathrm{O}_{8}$ \\
\hline Olivine $^{4}$ & 3.3 & $(\mathrm{FeMg})_{2} \mathrm{SiO}_{4}$ \\
\hline Bassanite & 2.3 & $\mathrm{CaSO}_{4} \cdot 0.5\left(\mathrm{H}_{2} \mathrm{O}\right)$ \\
\hline Akaganeite & 1.6 & $\mathrm{Fe}^{+3}(\mathrm{O}, \mathrm{OH}, \mathrm{Cl})$ \\
\hline Anhydrite & 1.3 & $\mathrm{CaSO}_{4}$ \\
\hline Hematite $^{4}$ & 0.8 & $\mathrm{Fe}_{2} \mathrm{O}_{4}$ \\
\hline Total & 100.0 & \\
\hline
\end{tabular}

${ }^{1}$ Elemental composition determined from refined lattice parameters

${ }^{2}$ Cation deficiency determined from refined lattice parameters

${ }^{3}$ Structure state determined from refined lattice parameters

${ }^{4}$ Considered to be contamination from previous sample 
amorphous material are shown in Table 2 . The composition of the amorphous component is found by subtracting the crystalline composition from the overall composition determined by the Alpha Particle X-ray Spectrometer (APXS) on MSL (Table 3).

MER-CLASS XRD/XRF ANALYSIS: CheMinX [4], a next-generation $\mathrm{XRD} / \mathrm{XRF}$ instrument, provides improved capabilities relative to CheMin, at one third the volume and one half the mass with reduced power requirements, in a package suitable for inclusion on MER-class rovers. It is now possible in a spacecraftcapable XRD to:

- Identify all minerals present $>1 \%$

- Quantify all minerals $>3 \%$ and determine their structure states

- Quantify all major elements present in each mineral ( $\mathrm{H}$ and above)

- Determine the valence state of all major elements $(\mathrm{H}$ and above), including speciation of multi-valent elements such as Fe.

- Determine the amount of X-ray amorphous material (if present).

There are no instruments currently in NASA's planetary inventory (other than CheMin) that can claim even one of these capabilities.
Table 2. Mineral, Clay Mineral and Amorphous Abundances in the Cumberland Mudstone

\begin{tabular}{|l|c|}
\hline \multicolumn{1}{|c|}{ Component } & Wt.\% \\
\hline Crystalline Minerals & 51 \\
\hline Smectite Clay & 18 \\
\hline Amorphous Material & 31 \\
\hline Total & $\mathbf{1 0 0 . 0}$ \\
\hline
\end{tabular}

Table 3. Normalized composition (oxide wt.\%) of Crystalline and Amorphous components

\begin{tabular}{|l|c|c|c|}
\cline { 2 - 4 } \multicolumn{1}{c|}{} & Total & Xtal. & Amorph. \\
\hline $\mathrm{SiO}_{2}$ & 41.13 & 46.93 & 25.56 \\
\hline $\mathrm{TiO}_{2}$ & 0.99 & 0 & 3.66 \\
\hline $\mathrm{Al}_{2} \mathrm{O}_{3}$ & 8.63 & 11.84 & 0 \\
\hline $\mathrm{Cr}_{2} \mathrm{O}_{3}$ & 0.46 & 0 & 1.7 \\
\hline $\mathrm{FeO}_{\mathrm{T}}$ & 21.95 & 23.41 & 18.03 \\
\hline $\mathrm{MnO}$ & 0.29 & 0 & 1.09 \\
\hline $\mathrm{MgO}$ & 9.32 & 6.28 & 17.53 \\
\hline $\mathrm{CaO}$ & 6.66 & 5.01 & 11.12 \\
\hline $\mathrm{Na}_{2} \mathrm{O}$ & 3.01 & 3.51 & 1.66 \\
\hline $\mathrm{K}_{2} \mathrm{O}$ & 0.62 & 0.65 & 0.53 \\
\hline $\mathrm{P}_{2} \mathrm{O}$ & 0.86 & 0 & 3.18 \\
\hline $\mathrm{SO}_{3}$ & 4.61 & 2.04 & 11.54 \\
\hline $\mathrm{Cl}_{3}$ & 1.19 & 0 & 4.40 \\
\hline $\mathrm{F}$ & & - & 0 \\
\hline $\mathrm{H}_{2} \mathrm{O}$ & - & 0.33 & - \\
\hline Prop. & - & $\mathbf{0 . 7 3 7}$ & $\mathbf{0 . 2 6 3}$ \\
\hline
\end{tabular}

MER-Class Arm-BaSed Elemental Imagery: On Mars landed missions to date, many features seen with arm-based optical imagery (concretions, veins, macroscopic crystals) cannot be uniquely identified or characterized because the elemental / mineral analysis instruments (APXS, Mossbauer) lack spatial resolution. The inclusion of an arm-based elemental imager along with an XRD/XRF will allow for structure, composition and morphology data to be collected contemporaneously, yielding a comprehensive and synergistic dataset for Earth-based interpretation.

MapX [5] is an imaging XRF Spectrometer suitable for moderate resolution $(\sim 100 \mu \mathrm{m})$ elemental imaging, small enough for inclusion on the arm of a MER-based rover. MapX is a fullframe elemental imager capable of analyzing samples in situ without sample preparation. MapX has no moving parts and a depth of focus of $\sim 1 \mathrm{~cm}$, and is designed to utilize ${ }^{244} \mathrm{Cm}$ radioisotope sources, eliminating the need for a High Voltage Power Supply or X-ray tube. Figure 3 shows a partial MapX dataset collected from a brecciated basalt infilled with hydrothermal carbonate 
cements from Spitsbergen, Norway (a terrestrial analog of the Comanche Carbonate analyzed by the APXS instrument on MER A [13-14].
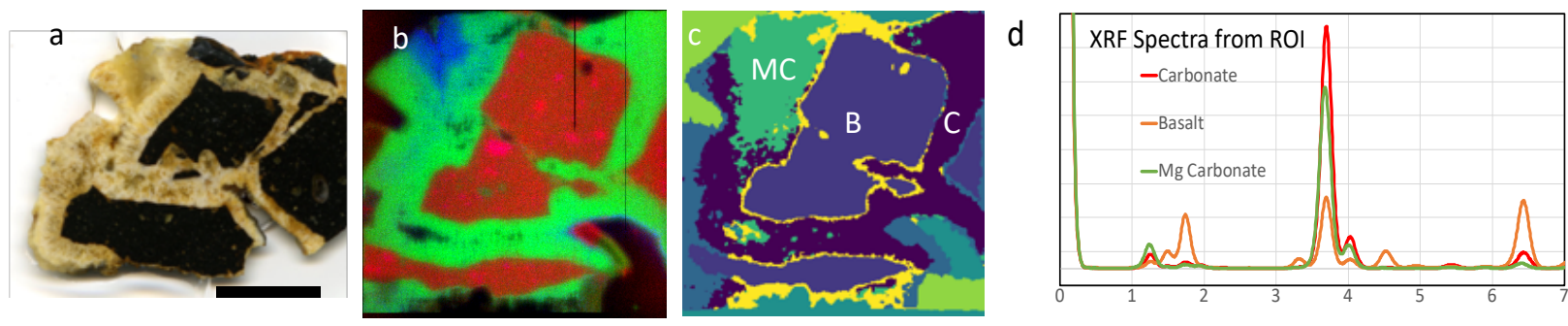

Figure 3. Basalt breccia cemented by carbonate. a). image of basalt breccia, scale bar $=1 \mathrm{~cm}$ (note: the image shown is the obverse of the side used for X-ray imaging); b). RGB image from MapX-III prototype, $\mathrm{Fe}=\mathrm{Red}, \mathrm{Ca}=\mathrm{Green}, \mathrm{Mg}=\mathrm{Blue}$; ). instrument selected Regions of Interest (ROI) having common compositions, $\mathrm{B}=$ basalt breccia, $\mathrm{C}=$ Carbonate, $\mathrm{MC}=$ magnesian carbonate; e). XRF spectra from ROI.

\section{CONCLUSION}

A MER-class rover equipped with a powdering drill, XRD/XRF and arm-based elemental imager, along with context instruments such as a Mast camera and hand-lens imager, will provide a comprehensive characterization of Mars surface regolith. A cookie-cutter approach to the development of a MER-class architecture suitable for multiple mission opportunities would reduce cost and risk. Only by accessing and fully characterizing multiple sites representing the full diversity of geologic and morphologic features on Mars will we be able to fully elucidate its early history and habitability potential.

\section{REFERENCES}

[1]. Grant, J.A., et al. (2010) "The science process for selecting the landing site for the 2011 Mars Science Laboratory." Planet. Space Sci., 59, 1114-1127, doi:10.1016/j.pss.2010.06.016.

[2]. Grant, J.A., et al. (2004). "Selecting landing sites for the 2003 Mars Exploration Rovers." Planet. Space Sci., 52, 11-21, doi: 10.1016/j.pss.2003.08.011.

[3]. Grant, J.A., et al. (2018). "The science process for selecting the landing site for the 2020 Mars rover.” Planetary and Space Science, doi: 10.1016/j.pss.2018.07.001.

[4]. Sarrazin, P. et al (2019), LPSC 50, abstr.\# 2236.

[5]. Blake et al., (2019). $9^{\text {th }}$ Int'l Conf. on Mars Abstr\# 6329.

[6]. Zacny, K., et al. (2013) IEEE Aerospace Conference, pp. 1-11, IEEE, Big Sky, Montana, March 2-9.

[7]. Grotzinger, J. P. et al. (2013). "A Habitable Fluvio-Lacustrine Environment at Yellowknife Bay, Gale Crater, Mars.” Science, 10.1126/science.1242777.

[8]. Vaniman, D.T., et al. (2013). "Mineralogy of a Mudstone on Mars." Science, 10.1126/science.1243480.

[9]. Bish, D.L. and J. E. Post (1993), Am. Min., 78, 932-940.

[10]. Morrison, S.M., et al. (2018a), American Mineralogist. DOI: 10.2138/am-2018-6123. 
[11]. Morrison, S.M., et al. (2018b), American Mineralogist. DOI: 10.2138/am-2018-6124.

[12]. Chipera S.J. and D. L. Bish (2002), J. Applied Crystallography 35, 744-749.

[13] Morris et al. (2010). "Identification of Carbonate-rich Outcrops on Mars by the Spirit Rover." Science, 329, 421.

[14]. Morris, R.V. et al, (2011). "A Terrestrial Analogue from Spitsbergen, (Svalbard, Norway) for the Comanche Carbonate at Gusev Crater, Mars.” LPSC 42, Abstr. \#2167. 